\title{
FÓRUM - CONHECIMENTO CIENTÍFICO EM MARKETING NO BRASIL: PERSPECTIVAS PARA 0 DESENVOLVIMENTO DA PESQUISA E DA TEORIA
}

\author{
Carlos Alberto Vargas Rossi \\ UFRGS \\ E-mail: cavrossi@ea.ufrgs.br \\ Salomão de Alencar Farias \\ UFPE \\ E-mail: saf@ufpe.br
}

\begin{abstract}
"Tudo o que o homem sabe é quase nada comparado com o que falta saber." A frase é do livro $O$ discurso do método, de Descartes, escrito em 1637. Livro de poucas páginas, permitiu ao seu autor ser lembrado como o primeiro filósofo moderno e um dos primeiros cientistas modernos. Descartes conduziu o leitor para além da trindade ateniense e dos escolásticos, ensejando a prática da inteligência individual e, por conseguinte, das rotas autodeterminadas.

O exercício do Marketing acadêmico no Brasil vive uma passagem nesta primeira década do século XXI. Pelas mãos de seus professores e pesquisadores, demonstrou ao longo dos anos sua incansável capacidade de produzir artigos, livros, dissertações e teses. A produção já é volumosa e continua a surgir, oferecendo-se caudalosamente nos EnAnpads e EMAs, além de persistentemente pedir passagem nas nossas revistas gerais de Administração, o que, por singela dedução, evidencia que uma revista de Marketing acadêmico também está a pedir passagem no Brasil.

A qualidade do conteúdo produzido avança proporcionalmente à quantidade, tanto em teoria quanto em método. Há alinhamento com o desenvolvimento das fronteiras da disciplina, e nossos trabalhos vêem-se incluídos em reputados congressos e, paulatinamente, periódicos internacionais. O que faltaria, contudo? Por que vivemos uma passagem?

A lacuna se localiza na autodeterminação de nossa
\end{abstract}

rota acadêmica. O tônus da produção científica gerada no Brasil, em Marketing, ainda é muito mais de adesão do que de criação. Seguimos o curso do desenvolvimento, mas predominantemente mimetizando-o, e portanto pouco concebendo de original, genuíno ou inovador na pesquisa e na construção de teoria. A constatação não reclama nenhuma produção acadêmica made in Brazil, dissociada do curso histórico de evolução do Marketing. Igualmente, não rotula simplesmente os professores e pesquisadores brasileiros de meros seguidores. Somos, tão-somente, parte dessa história do desenvolvimento científico em Marketing, reunindo as condições de amadurecimento do campo no país para sermos atores mais influentes no cenário de ponta de nossa disciplina. Essa influência tem suas exigências, seus passaportes de entrada. A criatividade e a inovação em pesquisa fornecem essas credenciais.

O Fórum "Conhecimento Científico em Marketing no Brasil: Perspectivas para o Desenvolvimento da Pesquisa e da Teoria" retrata uma pequena parte dessa trajetória. Os três artigos selecionados, dois de estratégia de marketing e um de comportamento do consumidor, representam dignamente a produção de duas áreas do conhecimento em Marketing que têm sido regularmente alvo de nossas pesquisas.

"Em busca de uma agenda brasileira de pesquisa em estratégia de marketing", de Alexandre Faria, e "Estratégia de marketing: contribuições para a teoria em Mar- 
keting", de Ana Maria Machado Toaldo e Fernando Bins Luce, expressam respostas significativas ao chamamento do tema do Fórum ao repercutirem aspectos muito identificados com as pesquisas da área no nível da estratégia, realizadas aqui no país.

Alexandre Faria escreve um artigo de alta conexão com a proposta deste Fórum. Em seu ensaio teórico, o autor reflete sobre a essência da pesquisa sobre estratégia em marketing em países periféricos como o Brasil. Reconhece, inicialmente, que a estratégia de marketing tem importância central para a disciplina por elevar a autonomia do marketing dentro da grande empresa e por transferir o controle estratégico do marketing desde a alta administração até os praticantes mais próximos ao mercado.

Valendo-se de uma abordagem sócio-histórica para o tratamento da estratégia em marketing, o artigo avança sobre o conceito de orientação para o mercado, considerando-o um dos principais obstáculos para o desenvolvimento da estratégia de marketing. Argumenta que os seus antecedentes históricos e as implicações correspondentes têm condições para ser atenuados por meio da constituição de uma agenda de pesquisa no Brasil, capaz de ajudar a resgatar a relevância da disciplina.

$\mathrm{O}$ autor defende que o desenvolvimento de agendas de pesquisa em estratégia de marketing pode ser particularmente importante em países periféricos, tais como o Brasil, devido a dois tipos de assimetria que foram evidenciados e ampliados pelo fenômeno da globalização: assimetria de mercado e assimetria acadêmica. $\mathrm{O}$ tom bastante crítico do autor, em relação à orientação para o mercado, perpassa uma revisão da literatura em três partes: na primeira, é desenvolvida uma análise histórica do Marketing nos Estados Unidos. Na segunda parte, apresenta o desenvolvimento da disciplina no contexto da guerra fria. E na terceira parte é discutida uma análise sócio-histórica do conceito de orientação para o mercado. Um pressuposto marcante, para o autor, é que o conhecimento dominante de marketing não pode ser tido como neutro, nem mesmo nos Estados Unidos.

A partir da revisão teórica, o texto indica que o conceito de orientação para o mercado estiolou o âmbito da estratégia de marketing e, conseqüentemente, também o interesse de pesquisadores por temas de poder e de implementação. O artigo esforça-se em mostrar que a disciplina de Marketing é importante demais para não contar com a constituição de agendas de pesquisa em países periféricos, que não devem, necessariamente, se basear na aversão à academia dos Estados Unidos. Para Faria, os pesquisadores em estratégia de marketing, no Brasil, devem reconhecer os mecanismos e os interesses históricos que vêm moldando a evolução da disciplina nos Estados Unidos. O final do artigo traz seis sugestões que podem guiar a constituição dessa agenda de pesquisa em estratégia de marketing no Brasil.

O segundo artigo sobre estratégia de marketing, de Ana Toaldo e Fernando Luce, adentra o espaço fronteiriço entre a estratégia empresarial e a estratégia de marketing. Esse terreno, imperfeitamente demarcado, oportuniza ao pesquisador a busca da complementaridade que pode tornar secundária a definição dos escopos de uma e outra.

Complementaridade, aliás, é a palavra que emblema o artigo. A formulação e a implementação da estratégia, as influências dos ambientes externo e interno sobre a estratégia, assim como o conhecimento sobre clientes e concorrentes são temas tratados no artigo, sempre convergindo na busca pela complementaridade.

Para fazer sua pesquisa, os autores tiveram na coincidência do ano de 1999 e no Journal of Marketing as suas fontes primordiais. Os modelos desenvolvidos e testados por Menon, Bharadwaj, Adidam e Edison (formação da estratégia de marketing) e por Noble e Mokwa (implementação da estratégia de marketing), combinados, propiciaram as bases para a construção do modelo teórico da pesquisa. Até na combinação desses dois modelos pode-se observar, uma vez mais, o intento da complementaridade.

Os construtos centrais do modelo teórico de formação da estratégia de marketing são os antecedentes, o processo e os resultados da estratégia. A idéia subjacente ao modelo é a desconstrução dos pressupostos de que (a) no momento da formulação há informações completas e suficientes, não se fazendo necessárias adaptações, e que (b) durante a implementação não haverá mudanças no ambiente externo. No entanto, o contexto ambiental se altera rapidamente, e as informações disponíveis são insuficientes. O ambiente induz a estratégia, que deve ser capaz de conduzir a um posicionamento de vantagem competitiva, influenciando a performance de mercado e a performance financeira da empresa. A formulação e a implementação de estratégias de marketing se configuram, então, como o desenvolvimento de atividades e tomada de decisões para construir e manter uma vantagem competitiva sustentável, entregando valor aos mercados.

Toaldo e Luce realizaram uma pesquisa em duas etapas: uma exploratória e qualitativa, e outra descritiva e quantitativa. Sucedendo a uma pesquisa exploratória feita em empresas, utilizaram a modelagem de equações estruturais sobre uma amostra final de 200 questionários. Essa amostra foi retirada de bancos de dados da revista 
Exame - Melhores e Maiores e da Fiergs (Federação das Indústrias do Estado do Rio Grande do Sul), e totalizou 1.271 empresas.

Os resultados abordaram as empresas em seu todo, no trabalho de construção e operacionalização de estratégias de marketing voltadas para a consecução dos objetivos organizacionais. Não foi considerada, portanto, apenas a área de Marketing. Tais resultados permitem depreender que, para elaborar uma estratégia de marketing, além de conhecer em profundidade clientes e concorrentes e dotar-se de competências de marketing, igualmente se faz necessário considerar questões internas da organização, como a comunicação, a integração, o comprometimento das pessoas, a cultura organizacional e a percepção sobre a importância da estratégia. Complementarmente, o artigo reitera a influência do macroambiente onde a empresa se insere.

Migrando da estratégia de marketing para a pesquisa do consumidor, o artigo "Dimensões culturais do marketing: teoria antropológica, etnografia e comportamento do consumidor", de Everardo Pereira Guimarães Rocha e Carla Barros, traz uma contribuição qualificada da pesquisa brasileira sobre o comportamento do consumidor em uma de suas manifestações: a investigação antropológica. A participação da pesquisa do consumidor no conjunto das pesquisas em Marketing, no Brasil, já há alguns anos não pára de crescer. Interdisciplinar por natureza, essa área vê-se assim muito bem representada no Fórum.
Em seu trabalho, Everardo e Carla convocam a Antropologia do Consumo e a Etnografia para a pesquisa em comportamento do consumidor. Nesse ensaio teórico, os autores examinam clássicos como Veblen, Durkheim, Mauss e Sahlins. Pesquisam também as publicações sobre Etnografia e Marketing, inclusive em revistas acadêmicas de Marketing, começando com Malinowski e a Etnografia em uma sociedade primitiva e avançando muito, até os tempos atuais, com as pesquisas de Kozinets nos meios de comunicação, com a Internet inclusa.

$\mathrm{O}$ artigo de Everardo e Carla, aproximando-se da pesquisa do consumidor no Brasil, dedica-se também à descrição de vários estudos desenvolvidos no âmbito da linha de pesquisa em Antropologia do Consumo do Coppead-UFRJ, com muita observação participante e pesquisas de estilo etnográfico. Trata-se, a bem da verdade, de descrição meritória, dada a produção gerada nesse tema, nesse instituto, nos últimos anos.

Dessa forma, nos encontramos no que chamamos de momento de passagem. Essa característica, tão forte e marcante no Marketing acadêmico brasileiro, representa que estamos, como disse Daniel Boorstin em Os investigadores, metidos entre duas eternidades: o passado que se foi e o futuro que não se conhece. No entanto, não seria ousadia antevermos que nos próximos anos, por evolução natural, teremos compromisso marcado com uma inserção mais ativa e expressiva na fronteira do conhecimento de nossa disciplina.

Artigo convidado. Aprovado em 04.09.2006. 